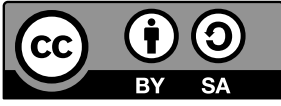

\title{
LA INFLUENCIA DEL TEATRO EN EL DESARROLLO DE LA DESTREZA ORAL Y EL DESCENSO DEL NIVEL DEL FILTRO AFECTIVO EN LA CLASE DE ELE
}

En el presente artículo nos centraremos en el uso del teatro en las clases de español como lengua extranjera (ELE), si bien los argumentos expuestos en este trabajo podrían aplicarse a cualquier otra lengua. Asimismo, entendemos que el término "teatro en la clase de ELE" está estrechamente relacionado con el concepto de continuidad, es decir, puede referirse tanto a las técnicas dramáticas (i.e. micro-actividades) como a las representaciones de obras enteras. Por lo tanto, nuestro trabajo se centra en la relación entre las clases de teatro, el factor afectivo y la destreza oral, así como los beneficios del uso de teatro en las clases de ELE. El objetivo principal del trabajo es explorar los potenciales efectos positivos del teatro en el desarrollo de la destreza oral de los estudiantes a través de un análisis cualitativo de entrevistas semi-estructuradas con un grupo de estudiantes universitarias de español que participaron en la clase de teatro español. Mediante el análisis de las experiencias personales de las estudiantes con el teatro, esta investigación examina la relación entre la participación en una clase de teatro y el nivel del filtro afectivo, la conexión entre la participación en una clase de teatro y la adquisición de la lengua y la relevancia de la participación de las estudiantes en la clase de teatro por su involucramiento activo en otras clases. EXTRANJERA

La importancia de los factores afectivos para el aprendizaje ha sido resaltada por muchas investigaciones contemporáneas (Arnold 2000, 2006; Sánchez Carrón 2013; Boquete Martín 2014, Pavlin 2017; Rosén 2018). Los factores afectivos pueden ser tanto negativos como positivos y deberían estar en el centro de atención de los maestros de ELE, ya que pueden o facilitar o dificultar el aprendizaje de la lengua extranjera. 
En el Marco Común Europeo de Referencia (MCER, Consejo de Europa 2002) se reconoce explícitamente la importancia de los factores afectivos en el proceso de aprendizaje. Hablando de la "competencia existencial" (saber ser), que forma parte de las competencias generales del alumno, se establece que

la actividad comunicativa de los usuarios o alumnos no solo se ve afectada por sus conocimientos, su comprensión y sus destrezas, sino también por factores individuales relacionados con su personalidad y caracterizados por las actitudes, las motivaciones, los valores, las creencias, los estilos cognitivos y los tipos de personalidad que contribuyen a su identidad personal (Ibíd.: 103).

De acuerdo con la ideología actual, una de las metas principales de los docentes de lenguas extranjeras es desarrollar la competencia comunicativa. A menudo esa meta resulta inalcanzable para los alumnos, a pesar de que objetivos comunicativos estén escritos en las programaciones y de que se intenten introducir actividades comunicativas. Una explicación puede ser que las restricciones temporales en el aula no coinciden con las necesidades de los alumnos. Por otro lado, la incompetencia comunicativa también puede ser producida por los factores afectivos (Arnold 2006: 409). En lo referente a los aprendientes eslovenos, Pavlin (2017: 227) observa que los eslovenos cultivan un tipo de "perfeccionismo lingüístico" que transmiten de la relación que tienen con la lengua materna y esto se está convirtiendo en una característica cultural de los eslovenos multilingües.

Arnold (2006: 409) establece que en la enseñanza de segundas lenguas tiene un papel transcendental "la disposición a comunicarse" (willingness to communicate). McCroskey y Richmond (1990: 21) la definen como una decisión volitiva de participar en un acto comunicativo.

Nuestros esfuerzos en el aula deberían centrarse en la estimulación del efecto de los factores positivos y la reducción del efecto de los factores negativos, entre los que destacan la ansiedad y la baja autoestima (Arnold 2006: 410). En cuanto a la ansiedad (Ibíd: 411), el profesor la puede reducir considerablemente con su actitud y con la atmosfera que crea en el aula. Asimismo, hay que "mantener una política sobre la corrección de errores que no resulta amenazante para el alumno" (Ibíd.: 412). Boquete Martín (2014: 7) coincide con Arnold y propone que "la corrección [se realice] cuando se produce una interrupción en la comunicación (o el desarrollo del ejercicio) antes que cuando se haya producido algún tipo de inexactitud o error fonético".

En una clase de LE con un enfoque comunicativo, la autoestima de los estudiantes adolescentes o adultos puede verse afectada de manera negativa, especialmente en las primeras fases del aprendizaje. Los alumnos tratan de expresarse, de comunicar a sus compañeros "ideas ya maduras con recursos lingüísticos inmaduros" (Arnold 2006: 410). 
La destreza que probablemente está más afectada por los factores afectivos negativos (auto-estima baja, ansiedad conectada con la competencia lingüística) es la destreza oral (Pavlin 2017: 224). De hecho, Šifrar Kalan (2008: 291) observa que "frecuentemente identificamos hablar una lengua extranjera con dominar la lengua extranjera, lo que sugiere que la expresión oral tiene un papel principal en el aprendizaje de una lengua extranjera"". Respecto a la destreza oral, Muñoz-Basols y Gironzetti (2018: 204) alegan que "con la integración de la tecnología dentro y fuera del aula, profesores y alumnos disponen hoy en día de un amplio abanico de recursos y herramientas para trabajar las destrezas orales". No obstante, los autores admiten que a pesar de la disponibilidad de los recursos, en el aula de español como L2 no se presta suficiente atención a la expresión oral (Ibíd.).

El MCER (Consejo de Europa 2002: 48) define comunicación oral como una de las dos actividades en las que el hablante transmite un mensaje hablado a uno o más oyentes/ interlocutores. Skela (1999: 100) afirma que la comunicación oral es un proceso bidireccional que requiere un hablante y un oyente, lo que no significa que el hablante sea la única persona que habla y que el oyente sea pasivo durante el intercambio oral. Cohen (2008: 122) observa que, para crear un acto comunicativo auténtico, es necesario que los hablantes y los oyentes colaboren. Por eso los profesores deben crear en la clase unas circunstancias adecuadas que permitan a los estudiantes combinar de manera significativa ambas destrezas (i.e. la destreza de hablar y la destreza de escuchar/entender) y participar en situaciones comunicativas auténticas (Skela 1999: 100).

Pavlin (2017: 224) retoma la idea de Skela (1999), quien alega que "la comunicación oral es la destreza lingüística más difícil de todas porque requiere el nivel de espontaneidad más alto, producir el texto y pensar al mismo tiempo, así como también un nivel de conocimiento formal de la lengua lo suficientemente alto como para evitar errores o corregirlos instantáneamente".

Muñoz-Basols y Gironzetti (2018: 205) se basan en la idea de Ramírez Martínez (2002) y explican que frecuentemente se considera que para adquirir la destreza oral no es necesaria la intervención directa del profesor, ya que los aprendices la adquieren espontáneamente, a través de la práctica. Según Skela (1999: 101), para alcanzar la fluidez en la lengua, se debe guiar a los estudiantes desde las actividades donde ellos solamente imitan un modelo hacia las actividades que requieren utilizar la lengua independientemente. Mientras que la lectura en voz alta, por ejemplo, es una de las actividades menos exigentes, las representaciones de obras de teatro pertenecen a la categoría de actividades que solicitan que los estudiantes usen la lengua más libremente (Ibíd.: 112-114).

1 Todas las traducciones españolas son nuestras. 


\section{4 \\ EL TEATRO COMO RECURSO PARA EL DESARROLLO DE LA DESTREZA ORAL EN LA CLASE DE LENGUA EXTRANJERA}

\section{1 El teatro y el Marco Común Europeo de Referencia}

¿Qué papel tienen la literatura y el teatro en una clase enfocada en la adquisición de la competencia comunicativa? En lo que atañe a los propósitos comunicativos de la lengua, Hidalgo Martín (2012: 16) observa que el MCER implica los "usos estéticos de la lengua", entre los cuales la autora destaca dos usos: representar obras de teatro con guion o sin él; presenciar y escenificar textos literarios como, por ejemplo, leer y escribir textos (relatos cortos, novelas, poesía, etc.); representar y presenciar como espectador recitales, obras de teatro y de ópera, etc. (Ibíd.). La autora añade que "entre la descripción de tareas recomendadas, el MCER propone la 'interpretación de un papel en una obra de teatro"' (Ibíd.).

Asimismo, la autora (Ibíd.) afirma que todas las subcompetencias (la competencia pragmática, sociolingüística y lingüística) de la competencia comunicativa se pueden desarrollar con la ayuda del teatro. En cuanto a la competencia lingüística, el aprovechamiento más grande se puede observar en el plano fonético-fonológico. Eso se debe al hecho de que en la fase de representación del texto se dedica mucha atención a la pronunciación y la prosodia. En lo que se refiere a los planos léxico y sintáctico, la misma autora (Ibíd.) admite que el uso puede resultar más problemático, puesto que el profesor puede enfrentarse con dificultades al buscar textos que fuesen compatibles con, por ejemplo, el nivel de conocimiento de sus estudiantes. Por lo que respecta al aspecto sociolingüístico, si bien escasea en muchas obras de teatro (lo admiten tanto Hidalgo Martín como el MCER), siempre se puede encontrar algunas obras que sí incluyen a ese aspecto. En cuanto a la competencia pragmática, Hidalgo Martín (2012:17) aduce que "el trabajo sobre esa tipología textual, tan completa por la cantidad de hablantes que intervienen en ella y por la variabilidad de contextos y situaciones, nos ofrece un recurso magnífico para trabajar la ironía, la parodia y los actos de habla, por ejemplo".

En lo referente a las cuatro destrezas, para conseguir un buen producto, en un primer lugar son imprescindibles la lectura y la comprensión de la obra. También es importante que el estudiante comprenda a sus compañeros y a las instrucciones del profesor/director. Mientras que la expresión oral es importante a la hora de hacer actividades para mejorar la dicción, la expresión escrita se practica, por ejemplo, cuando los estudiantes hacen anotaciones, escriben listas de materiales, cartas o resúmenes (Hidalgo Martín 2012: 18).

\subsection{Por qué usar el teatro en la clase de ELE}

\subsubsection{La situación actual}

En lo que respecta al teatro en español en Eslovenia, actualmente hay un interés considerable en la lengua y cultura española. En consecuencia y debido a las muchas oportunidades 
para aprender español, hay numerosos grupos de teatro que representan obras de teatro en español tanto en escuelas secundarias como en la Facultad de Filosofía y Letras en Ljubljana (activo desde 1999) (RTVSLO.si 2009).

\subsubsection{Ventajas del uso}

Hay varias ventajas del uso de teatro en la clase de una lengua extranjera. A continuación, enumeramos algunos beneficios que nos parecen los más relevantes. El uso del teatro en la clase es compatible con el enfoque comunicativo. Nicolás Román (2011 en Vaqueiro Romero 2014: 38), afirma que está claro que el uso del teatro en la clase está basado en el enfoque comunicativo, ya que los estudiantes trabajan en grupos y tienen el papel de protagonistas en su aprendizaje. Sirisrimangkorn (2018: 14) se basa en la idea de Miccoli (2003), quien explica que en los ensayos de teatro se crea un auténtico propósito comunicativo cuando los estudiantes deben establecer los personajes, sus personalidades y motivos.

La participación en actividades teatrales también motiva a los estudiantes. Maley y Duff (1982:13) sostienen que "el teatro es motivador". Cuando los estudiantes participan en un grupo de teatro, esto no solo ayuda a cultivar su curiosidad sobre la lengua, sino que también les motiva más para usar la lengua meta (Lemut Novak 2009; Sirisrimangkorn 2018).

Es más, el teatro ayuda a bajar el filtro afectivo. En las clases o talleres de teatro, los estudiantes son proclives a explorar la lengua extranjera de una manera más relajada, ya que la atmósfera de confianza que se ha establecido les anima a dejar de bloquear el nuevo lenguaje, a tomar riesgos y sentirse estimulados de manera positiva (Williams-Fleck 2014: 13; Boudreault 2010).

El teatro, asimismo, estimula la confianza que los estudiantes tienen en su habilidad de hablar una lengua extranjera. Heldenbrand (2003: 31) explica que, en el escenario, ser exacto a la hora de hablar es menos esencial que poder comunicar las ideas. El enfoque está en equipar a los estudiantes para que comuniquen en la lengua meta y no en el habla exacto.

En las clases de teatro los estudiantes pueden practicar y desarrollar su competencia oral, en particular la pronunciación y la fluidez (Boquete Martín 2014; Lemut Novak 2009). Los estudiantes también practican la entonación, acentuación y la pronunciación en la lengua meta (Lemut Novak 2009: 37).

El teatro es una herramienta útil en la enseñanza de lenguas porque permite que los estudiantes adquieran nuevos elementos del vocabulario de una manera plenamente contextualizada (Boudreault 2010). Aparte del vocabulario, los estudiantes también practican el orden de las palabras y las estructuras sintácticas (Lemut Novak 2009: 37).

En cuanto a la cultura de la lengua meta, el teatro nos puede ayudar a acercarla a los estudiantes . Williams-Fleck (2014: 13) se apoya en la idea de Miccoli (2003) afirmando que "la lengua no solo son palabras que se dicen, sino que también incluye cómo los hablantes nativos interactúan entre sí, se estrechan las manos, sostienen su cuerpo, etcétera".

Autores como Boquete Martín (2014: 19), Hidalgo Martín (2012: 23) y Boudreault (2010) declaran que el teatro puede ayudar a desarrollar el pensamiento crítico y la 
creatividad de los estudiantes. Según Hidalgo Martín (2012: 23), la creatividad surge tanto cuando los alumnos buscan argumentos y la trama como cuando buscan soluciones para montar la presentación de la obra de modo apropiado (por ejemplo, buscan un posible escenario, se distribuyen los papeles, preparan los materiales, etc.). La misma autora (Ibíd.) explica que el pensamiento crítico se desarrolla "comentando aspectos de la obra o del montaje con los que están o no de acuerdo".

\subsubsection{Inconvenientes del uso}

Hay una abundancia de ventajas al usar las técnicas dramáticas en clase, o incluso al realizar un taller de teatro. Sin embargo, hay que tener en cuenta también algunos inconvenientes. Desde el punto de vista del profesor, organizar una clase de teatro significa que tiene que asumir un volumen de trabajo adicional por el cual tal vez no será remunerado (Lemut Novak 2009:38). Es esencial que el profesor sepa motivar a los alumnos y que, en caso de no ser nativo, tenga la suficiente fluidez y sea capaz de una comunicación eficaz en la lengua meta (Hidalgo Martín 2012: 27).

Respecto a un taller de teatro, Hidalgo Martín (2012: 27) observa que "lo que sí parece un problema es el afán de protagonismo de algunos estudiantes que puede ser contraproducente, ya que algunos estudiantes, los más tímidos, pueden cohibirse por la extroversión de estos". El profesor, entonces, debe "intentar dar las mismas oportunidades a todos buscando opiniones consensuadas" (Ibíd.). Asimismo, Hidalgo Martín expone que, para proteger la autoestima del alumno, es imprescindible "ir graduando las actividades que supongan mayor riesgo para la imagen personal” (Ibíd.).

Otro reto al que los profesores pueden enfrentarse es que no es fácil encontrar textos para niveles bajos de competencia. En general, los textos no están adaptados para el uso en el aula, lo que significa que abundan en coloquialismos y juegos de palabras, que a veces resultan difíciles de entender incluso para los niveles más altos. No obstante, con un poco de perseverancia se pueden hallar textos interesantes y motivadores también para los alumnos de niveles bajos (Ibíd.).

Por último, creemos que la responsabilidad del grupo a veces también puede ser problemática. Las clases de teatro, especialmente cuando se planea una presentación final, requieren un esfuerzo de todo el grupo y muchas veces es difícil de conseguir que todos los miembros del grupo hagan las tareas asignadas (por ejemplo, lean el texto en casa, vengan a la clase, estudien su personaje, preparen el vestuario) con el mismo grado de responsabilidad. Por eso, el trabajo de equipo, tanto dentro como fuera del escenario es esencial para el buen funcionamiento del grupo. 


\subsection{Preguntas de investigación}

Nuestra investigación examinó la influencia del teatro en el desarrollo de la destreza oral de un grupo de estudiantes de la Facultad de Filosofía y Letras en Ljubljana desde la perspectiva de los propios estudiantes. El propósito de dicha investigación fue llamar la atención sobre el teatro como una herramienta de gran alcance en la clase de lengua extranjera en lo que se refiere al desarrollo de la destreza oral, así como promover el teatro como un instrumento que ayuda a los estudiantes a superar la ansiedad conectada con la competencia lingüística. Esos objetivos llevaron al planteamiento de las siguientes preguntas de investigación:

- ¿La participación en las clases de teatro ayuda a los estudiantes a confiar más en su destreza oral? ¿Les ayuda a perder el miedo de hablar en la lengua extranjera?

- ¿Los estudiantes consideran el teatro como algo beneficioso para la adquisición de la lengua extranjera? ¿Sienten que el teatro les ayuda a mejorar su destreza oral?

- ¿Si los estudiantes participan en una clase de teatro, esto también favorece a su participación en otras clases?

\subsection{Metodología}

Esta investigación está basada en el enfoque cualitativo, porque nos pareció más flexible y compatible con el tipo de datos (experiencias personales, subjetivas) que necesitábamos recopilar; de ahí que nos interesara investigar una muestra de menor tamaño, pero con mayor profundidad. Según Dörnyei (2007: 24) "una investigación cualitativa implica procedimientos de recopilación de datos que primordialmente resultan en datos abiertos, no-numéricos, que luego se analizan con métodos no-estadísticos". Es decir, las entrevistas fueron realizadas con el objeto de obtener los datos necesarios para que, a continuación, fueran interpretadas las respuestas de las entrevistadas de modo descriptivo. El objetivo final de la investigación cualitativa no es determinar "en qué grado la muestra es representativa o cómo se distribuye la experiencia entre la población" (Dörnyei 2007: 126). La meta principal de este tipo de exploración es "encontrar individuos que pueden proveer observaciones ricas y variadas sobre el fenómeno bajo investigación para maximizar lo que se puede aprender" (Ibíd.).

\subsection{Descripción del instrumento y del proceso de recopilación de los datos}

El formato utilizado fue entrevista semi-estructurada que según Dörnyei (2007: 136) significa que "hay una serie de preguntas orientadoras preparadas de antemano [...] [pero 
al mismo tiempo] el formato es abierto y se alienta al entrevistado a que ahonde más en las cuestiones planteadas de modo exploratorio". En todas las entrevistas llevadas a cabo fueron planteadas las mismas doce preguntas que habían sido preparadas con antelación. No obstante, durante cada entrevista individual también fueron añadidas algunas preguntas adicionales con el objeto de precisar o añadir alguna aclaración. Para el diseño del cuestionario, nos basamos parcialmente en Goitia Pastor (2007: 108-109).

La pregunta 1 requirió que las estudiantes evaluaran su competencia en español. Las preguntas 2 y 3 se centraron en el factor afectivo en la clase de ELE. Su propósito fue descubrir los sentimientos que acompañan la expresión oral y cómo los estudiantes abordan la expresión oral en la clase de ELE. Las preguntas 4-8 abordaron el tema del teatro. Exploraron potenciales experiencias previas de las estudiantes con teatro y las razones por las que decidieron participar en las clases de teatro en la Facultad de Filosofía y Letras en Ljubljana. Asimismo, las preguntas examinaron qué sintieron las estudiantes cuando actuaron en la lengua extranjera. También se investigó la influencia del teatro en el progreso de las estudiantes en lo que se refiere a la ansiedad y competencia lingüística. Las preguntas 9 y 10 pretendieron identificar la influencia de las clases de teatro en la expresión oral de las estudiantes y en su participación en otras clases. Se pidió a las estudiantes evaluar el progreso de sus compañeros de clase con la pregunta 11. La pregunta final requirió que las estudiantes declararan si les gustaría participar en otra clase de teatro o no. Para asegurarnos de que las preguntas proveyeran a la investigación de los datos adecuados, diseñamos una entrevista piloto con dos estudiantes de español llevada a cabo en abril de 2019. El perfil de los estudiantes con los que se hizo la entrevista piloto coincidía con el perfil de las estudiantes que fueron después participantes de investigación. Como la información obtenida del pilotaje no coincidía totalmente con los objetivos planteados por las hipótesis, hubo que introducir algunos cambios.

En lo que se refiere al proceso de recopilación de datos, primero se contactó con la profesora Santiago Alonso que imparte la clase de teatro español. Le explicamos a la profesora qué tipo de investigación vamos a hacer, cuál es el propósito y qué características necesitan exhibir los participantes. Con la ayuda de la profesora escogimos dos estudiantes para la entrevista piloto. Después, la profesora escribió un correo electrónico a las candidatas; les explicó el tema general de la investigación y el formato, y les preguntó si estarían dispuestas a participar. Cuando las estudiantes le confirmaron su disposición, la profesora nos facilitó sus correos electrónicos. Contactamos a las estudiantes por el correo electrónico, nos introducimos y les presentamos el tema de nuestra investigación. Les agradecemos por su disposición y les preguntamos cuándo podrían reunirse con nosotros para la entrevista.

Las entrevistas se realizaron entre mayo y octubre de 2019, y tomaron lugar en la Facultad de Filosofía y Letras en Ljubljana, después de las presentaciones de las obras. Al principio de las entrevistas se les explicó a las estudiantes cómo se grabará la conversación y qué pasará con los datos después. Además, se les aseguró que serán anónimas. También 
se informó a las participantes aproximadamente cuánto tiempo durará la entrevista. Enfatizamos que no hay respuestas erróneas, que nos interesan sus experiencias.

Las preguntas fueron preparadas en esloveno y español, ya que una de las entrevistadas era montenegrina. Las primeras preguntas (por ejemplo: ¿Qué tal?) nos sirvieron para crear la atmosfera de confianza y para establecer la relación con las entrevistadas. Después de estas preguntas, empezamos con las preguntas de contenido (content questions). Dimos a las entrevistadas el tiempo que necesitaban para pensar y respondernos. El promedio de duración de las entrevistas fue 40 minutos. Las conversaciones fueron grabadas y también tomamos algunas notas. Tuvimos cuidado para no reaccionar demasiado fuerte (por ejemplo, tomar notas con mucho entusiasmo, reaccionar con mucha sorpresa) a algo que dijeron las entrevistadas, ya que esto podría influir en sus respuestas a preguntas futuras.

Las conversaciones fueron transcritas después de hacer las entrevistas. Imprimimos las transcripciones y las re-leímos varias veces para formar las impresiones generales sobre los datos. Luego preparamos los rotuladores fluorescentes de diferentes colores y leímos las transcripciones de nuevo. Esta vez, resaltamos los fragmentos relevantes y añadimos los códigos al lado del texto (los códigos, por ejemplo, fueron: el miedo de hacer errores, la confianza, estar relajado, la ansiedad social, la comunicación). Más adelante, leímos todos los fragmentos resaltados de nuevo y comparamos los códigos de los fragmentos entre sí. Agrupamos los códigos que fueron similares o relacionados entre sí en categorías más generales (por ejemplo: los códigos el miedo de hacer errores, la confianza, estar relajado, la ansiedad social, la comunicación se agruparon en categoría Los beneficios de las clases de teatro en cuanto al factor afectivo).

\subsection{Descripción de las participantes}

Las entrevistas fueron planteadas a cuatro estudiantes de español que participaron en la clase de teatro en el año académico 2018/19. Todas las entrevistadas tuvieron que exhibir por lo menos una de las siguientes características: tener un conocimiento de la lengua española bajo o ser tímidas. Si la entrevistada tuvo el conocimiento de lengua bajo, se investigó la influencia de este factor en su disposición a participar en comunicación oral. Si la entrevistada tuvo el conocimiento de lengua bajo y también fue tímida, se investigó la influencia de los dos factores en su disposición a participar en comunicación oral. La timidez de las participantes se identificó con la ayuda de la profesora que tuvo la clase de teatro con las participantes y pasó mucho tiempo con ellas. En las entrevistas se comprobó la timidez también por nuestra parte. No era necesario que las estudiantes tuvieran alguna experiencia con las clases de teatro antes de participar en la clase de teatro en la Facultad. Las primeras tres entrevistadas participaron en la presentación de la obra de teatro Dios en la Niebla escrita por Natalia de la Llana, mientras que la cuarta entrevistada 
participó en el montaje de la obra El lector por horas escrita por José Sanchis Sinisterra. En ambos casos, la clase de teatro duró un semestre.

A continuación se presentan los perfiles de las entrevistadas. La primera entrevistada (SSP1) fue una estudiante montenegrina que vino a Eslovenia para estudiar. Fue estudiante de español e italiano y empezó a estudiar español en la facultad. Tuvo 20 años. Cuando tuvo lugar la entrevista, el nivel de competencia lingüística de la estudiante fue A2. No fue tímida. En cuanto a sus experiencias con el teatro, la estudiante formo parte de grupo de teatro montenegrino y grupo de teatro francés en la escuela secundaria (4 años). La segunda entrevistada (SSP2) fue estudiante de español e inglés. Fue tímida. Tuvo 20 años. Cuando tuvo lugar la entrevista, el nivel de competencia lingüística de la estudiante fue B1/B2. En lo referente a sus experiencias con el teatro, la estudiante formó parte de un grupo de teatro en la escuela primaria. También participó en un grupo de teatro en la escuela secundaria (3 años). La estudiante formó parte del grupo de teatro español y del club de teatro inglés en la Facultad de Filosofía y Letras en Ljubljana (1 año). La tercera entrevistada (SSP3) fue estudiante de español e historia. Fue tímida. Tuvo 21 años. Cuando tuvo lugar la entrevista, el nivel de competencia lingüística de la estudiante fue B1+. Respecto a sus experiencias con el teatro, la estudiante participó en un grupo de teatro en la escuela primaria. La cuarta entrevistada (SSP4) fue estudiante de español y latín que aprendió español en la escuela secundaria, pero se tomó un año sabático y olvidó mucho. Fue tímida. Tuvo 22 años. Cuando tuvo lugar la entrevista, el nivel de competencia lingüística de la estudiante fue B2. En cuanto a sus experiencias con el teatro, la estudiante formó parte del grupo de teatro esloveno en la escuela secundaria.

\subsection{Pregunta de investigación 1: Relación entre la participación en las clases de teatro y el factor afectivo}

En cuanto al factor afectivo, la estudiante SSP1 mencionó que el teatro le "[ayudó] quitar la (...) el miedo un poco, el miedo de hacer errores en español, porque fu[e] muy estresada, porque eso fue el principio". La estudiante SSP2 declaró que "sient[e] que esta clase [1]e hizo sentir aún más segura a la hora de hablar en español". De modo similar, la estudiante SSP3 observó que "definitivamente fu[e] un poco más relajada al final". Según la estudiante, la actitud de la profesora fue esencial, ya que "siempre enfatizaba que era importante estar relajado y decir la primera cosa que [les] vino a la mente [y esto le ayudó] a salir de [su] zona de confort". También se mencionó un beneficio no lingüístico. La estudiante SSP4 confesó que la clase de teatro "[1]e ayudó con [su] ansiedad social," añadiendo que "[a]hora para [ella] es más fácil comunicar con la gente en general".

Las opiniones de las estudiantes de español en cuanto al progreso de sus compañeros variaron. La estudiante SSP1 alegó que "piens[a] que esto depende mucho de persona". 
Explicó que "había algunas personas que fueron muy cerradas, pero no vi[o] que ellos querrían [...] mejorar esto. Aunque [la profesora de teatro] ha tratado de [...] ayudarles. Ella trató de ayudar a todos y trató de ayudarles perder el miedo". No obstante, la estudiante también admitió que probablemente no es la mejor fuente de información, ya que "no estuv[o] tan atenta de[1] progreso [de los demás]". Por otro lado, las estudiantes SSP3 Y SSP4 tuvieron una opinión diferente. La estudiante SSP3 declaró que "[1]e parece que fu[e] entre los estudiantes más reservados. Pero piens[a] que otros estudiantes con ese problema también progresaron". De modo similar, la estudiante SSP4 declaró que "cre[e] que todos progresaron," añadiendo que "la diferencia se pud[ó] observar ya el primer semestre".

Todas las estudiantes de español afirmaron que la actitud de la profesora y su reacción a los estados de ánimo de estudiantes fueron esenciales, ya que la profesora se aseguró de que los estudiantes estuvieran relajados a través de actividades que les animaran a relajarse. La estudiante SSP2 mencionó que "trabaja[ron] en algunas escenas, que [uno de los compañeros] presentó una escena y después otra persona tuvo que resumirla." La estudiante explicó que "todos, incluso los estudiantes más reservados tuvi[eron] que decir qué pasó. [La profesora] insistió que cada estudiante encontrase la respuesta cuando fue su turno. Fue necesario hablar, y la próxima vez cuando tuvi[eron] la clase de teatro, no [se] sentí[an] tan forzados a hablar". En lo referente a la actitud de la profesora y las actividades relajantes, la estudiante SSP3 alegó que "forma[ron] un círculo y cada uno de [ellos] tuvo que decir la primera palabra española que [les] vino a la mente. Cuando terminó la primera ronda, [la profesora] leyó [su] lenguaje corporal y entendió que [la estudiante] no [s]e sentía muy cómoda”. Después de un par de actividades, la profesora "logró que [la estudiante] [s]e relajó físicamente y que fu[e] capaz de decir la primera cosa que le vino a la mente". La estudiante SSP4 sostuvo que "no [podía] acordar[se] de ninguna actividad beneficiosa específica", pero añadió que "el proceso en su conjunto fue beneficioso". También confesó que "[1]e gusto la actitud de la profesora". Explicó que la profesora "vio inmediatamente que [la estudiante] no [s]e sentía relajada, sin embargo, no estaba emitiendo la vibra de ¿¿Qué haces tú aquí?”.

En lo referente al factor afectivo en el presente, todas las estudiantes de español alegaron que ahora están (aún) más relajadas cuando tienen que hablar en español. La estudiante SSP1 alego que "si compar[a] Morfosintaxis 1 y Morfosintaxis 2, en Morfosintaxis 1 cuando hici[eron] ejercicios de gramática no quis[o] decir nada, siempre tenía miedo de que v[a] a hacer un error y ahora pued[e] preguntar si no entiend[e] [algo]". La estudiante añadió que "todo esto empezó en el teatro". La estudiante SSP2 afirmó que "ahora [es] más relajada en otras clases también" y que "ahora ya no se preocupa por si [hizo] algún error porque en la clase de teatro [se] acostumbraron a no preocuparse si alguien dijo algo incorrectamente o si hizo un error gramatical". Explicó que "[la profesora] [les] dijo al principio que no va[n] a tratar ese tema porque no está[n] [allí] para tener una gramática perfecta. [Les] dijo que hay otras asignaturas para ayudar[les] con eso; el objetivo de [la clase de teatro] fue ayudar[les] a hablar con más fluidez y a ser menos 
reservados a la hora de hablar". La estudiante SSP3 admitió que, en cuanto a su estado de relajación, "esto depende de con quién habl[a]. [S]e sient[e] totalmente relajada en compañía de ciertas personas, y en compañía de otras, no." Elaboró que "tal vez todavía no [s] e siente relajada [si tiene que hablar] ante un grupo en la facultad. Si fuese un grupo pequeño de 10-15 estudiantes, entonces tal vez [s] sentiría mejor". La estudiante SSP4, por otro lado, alegó que "ahora v[a] a decir algo aunque no sea totalmente correcto," y añadió que "ahora [s]e sient[e] más relajada":

Como demostraron los resultados del análisis cualitativo en la presente investigación, es recomendable participar en las actividades teatrales por varias razones. En lo que se refiere al factor afectivo, los resultados de la investigación muestran que la participación en una clase de teatro reduce el miedo de hacer errores a la hora de hablar una lengua extranjera. El filtro afectivo disminuye porque, en una clase de teatro, el énfasis está en la transmisión del mensaje y no tanto en la precisión lingüística. También es importante la actitud positiva del profesor hacia los errores. Las actividades que ayudan a los estudiantes a perder el miedo en una clase de teatro son las actividades comunicativas que requieren que los estudiantes superen sus miedos y participen activamente. Según los resultados, las actividades beneficiosas específicas son: La actividad que requiere el resumen de una escena y la actividad de asociaciones, hecha en un círculo.

\subsection{Pregunta de investigación 2: Posibles beneficios del teatro para la adquisición de una lengua extranjera y el mejoramiento de la destreza oral}

La mayoría de las estudiantes de español afirmó que su participación en actividades teatrales tuvo una influencia positiva en la adquisición de la lengua. La estudiante SSP1 señalo que "[c]uando terminó el teatro, fue una lección muy buena para [ella]. De este punto hi[zo] una aproximación, [s]e acer[có] más [al estudio de español]. [L]e ayudó a ser aún más espontanea en [su] expresión oral. Claramente, [su] español ha mejorado mucho después de esto". En lo que se refiere al enriquecimiento del vocabulario, la estudiante SSP2 hizo una observación interesante alegando que después de la clase de teatro "us[ó] ciertas palabras o frases que aparecieron en el texto [la obra de teatro] cuando escrib[ió] los ensayos, así como también cuando tuvo otras clases y cuando conversaba". Por otro lado, la estudiante SSP3 declaró que "piens[a] que la clase de teatro no [1]e ayudó a adquirir ninguna palabra o frase nueva". En contraste con esta estudiante, la estudiante SSP4 afirmó que "cre[e] que esta clase [1]e ayudó a adquirir las estructuras, [a aprender] cómo decir algo (por ejemplo: qué tiempo verbal utilizar). [...] También empe[zó] a usar más las palabras que aprend[ió] del texto".

Respecto a la destreza oral, todas las estudiantes de español señalaron que la clase de teatro tuvo un impacto positivo en su destreza oral. La estudiante SSP1 observó que "Si emp[zara] el año con la gramática todo el tiempo, nada hablar no est[á] segura si ahora 
hablaría tan bien como habl[a]". En lo referente a las características fonéticas y prosódicas de la lengua, la estudiante SSP2 hizo una observación intrigante. Señaló que "piens[a] que estuv[o] rodeada de los compañeros de clase que tenían una pronunciación muy buena, y si estas en la compañía de tales personas, tu pronunciación mejora también". La estudiante SSP3 confesó que "al principio, piens[a] que [1]e dificultó la participación el hecho de poder observar la diferencia entre el grado de [su] competencia y el grado de la competencia de los demás. Esa diferencia [1]e hizo abstener de comunicación, apenas pud[o] decir algo en español. Pero después, en las clases de teatro, fue un poco más fácil”. Además, la estudiante SSP3 hizo una observación importante. Sostuvo que "no est[á] segura si deb[e] atribuir [su progreso] a la clase de teatro, al hecho de que trabaj[a] para la organización Nefiks, o a otras asignaturas, más enfocadas en la gramática”. La estudiante concluyó que su progreso "probablemente es [el producto de] la combinación de todos los factores mencionados". La estudiante SSP4 alegó que "[las clases de teatro] tuvieron un efecto positivo. [L]e parece que todavía est[á] quedándo[se] atrás de [sus] compañeros, pero aún así, cre[e] que [las clases de teatro] [1]e ayudaron".

Por lo que respecta a la adquisición de la lengua, los resultados muestran que las clases de teatro pueden ayudar a los estudiantes a alcanzar una mayor espontaneidad en la lengua extranjera. La participación en una clase de teatro también les puede ayudar a enriquecer su vocabulario y a comprender mejor la gramática (por ejemplo, cuándo usar ciertos tiempos verbales, o cómo expresar ciertas funciones de lengua).

En cuanto al desarrollo y mejoramiento de la destreza oral, los hallazgos indican que las clases de teatro pueden ayudar a los estudiantes en esta área. La participación en una clase de teatro puede ayudar a los estudiantes a mejorar su pronunciación cuando están rodeados de un profesor y compañeros de clase con una buena pronunciación.

\subsection{Pregunta de investigación 3: Relación entre la participación en las clases de teatro y la participación activa en otras clases}

Todas las estudiantes de español afirmaron que ahora participan activamente en las clases. La estudiante SSP1 confesó que ahora participa más "gracias a muchas cosas, pero la clase de teatro fue el clave. Ahora no t[iene] miedo de hacer errores. Si compar[a] Morfosintaxis 1 y Morfosintaxis 2, en Morfosintaxis 1 cuando hici[eron] ejercicios de gramática no quis[o] decir nada, siempre tenía miedo de que $\mathrm{v}[\mathrm{a}]$ a hacer un error y ahora pued[e] preguntar si no entiend[e] [algo]". La estudiante SSP2 sostuvo que "cre[e] que ahora particip[a] más que al principio, pero [que a ella le] molesta en general si hay un silencio horrible cuando el profesor pregunta algo y (...) di[ce] algo, aunque s[abe] que puede ser que no sea totalmente correcto en cuanto a la gramática". En cuanto a la participación activa en otras clases, la estudiante SSP3 "diría que se puede observar una diferencia, pero no s[abe] a qué exactamente deb[e] atribuirlo. Probablemente es el resultado de muchos factores, como ya mencion[ó]. Pero, se puede observar la diferencia." De modo similar, 
la estudiante SSP4 declaró que "diría que otras asignaturas también contribuyeron a eso". La estudiante añadió que "[1]e parece que el teatro más bien [1]e ayudó [...][a] entender que sueña español, y no a hablar con más fluidez. Pero [1]e ayudó a estar más relajada cuando habl[a] en español".

Además, en las entrevistas la mayoría de las estudiantes de español declaró que ahora asumen un rol activo en los debates en clase. La estudiante SSP1 señaló que "por ejemplo, en la clase de prof. Alejandro [...] el profesor a veces [la] corrige, o una amiga [1]e ayuda con alguna palabra, pero [que] esto no [1]e frustra". Asimismo, la estudiante SSP2 afirmó que "habl[a] mucho [...] [y] [1]e gusta expresar [su] opinión y si t[iene] que hacerlo en la clase de español, esto no es un problema para [ella]. A veces le pid[e] ayuda a la compañera de clase si no conoce alguna palabra, pero aparte de esto, todo está bien". La estudiante SSP3 confesó que "cuando el tema [1]e interesa (por ejemplo: la crítica social), [1] gustaría participar [en el debate]". Elaboró que "si el debate fuese en esloveno, definitivamente levantaría la mano, pero aún $\mathrm{t}$ [iene] algunas reservas si el debate es en español. De modo normal, esper[a] un poco, y después, si realmente no est[á] de acuerdo con algo que alguien dijo, o si [1]e llama el profesor, di[ce] algo". La estudiante SSP4 observó que "de hecho, [s]e ofre[ce] a hablar porque normalmente ti[enen] debates interesantes, y a pesar de todo [ella] quiere decir algo". Explicó que "al principio del primer año esper[ó] que no [la] llamaran nunca, para poder guardar silencio. [Ahora] a veces es difícil para [ella] decir lo que quier[e], pero a pesar de esto, [s]e ofre[ce] a hablar".

Los datos recogidos mostraron que, en mayoría, las estudiantes ahora participan más activamente en otras clases y asumen un papel activo en los debates. En general, si las estudiantes no conocen alguna palabra o no saben cómo exactamente decir algo, esto ya no reprime su voluntad de comunicar en español. El hecho de que las estudiantes ahora participan más en las clases podría ser el producto de diferentes factores. No obstante, los datos recogidos sugieren que las clases de teatro pueden considerarse uno de esos agentes.

\subsection{Observaciones generales}

Los hallazgos de esta investigación podrían servir tanto a los aprendientes como a los profesores de lenguas extranjeras en todos los niveles educativos, ya que tanto en la escuela primaria, como en la escuela secundaria o en la universidad se puede encontrar con alumnos que tienen nivel de conocimiento entre A2-B2 (como las entrevistadas de esta investigación). Los resultados mostrarán a los estudiantes los beneficios de participar en una clase de teatro y los animarán a participar en las actividades teatrales y en las clases de teatro. En cuanto a los profesores de lenguas extranjeras, los resultados los animarán a incluir las actividades teatrales en sus clases. Además, estimularán a los profesores para ofrecer a sus estudiantes las clases de teatro como una asignatura opcional. Esta investigación también podría servir a otros investigadores proveyéndoles con información 
adicional sobre la utilidad de las clases de teatro en cuanto a la reducción del filtro afectivo, la adquisición de la lengua y el desarrollo/mejoramiento de la destreza oral.

En lo referente a la mejora de la destreza oral, la adquisición de la lengua y la bajada del filtro afectivo, los resultados también coinciden con los hallazgos obtenidos por Hidalgo Martín (2012: 53) y Čamernik (2018: 83-85). Este sincronismo de resultados sugiere que sería buena idea dedicar más espacio físico y curricular al teatro. El teatro debe continuar siendo una asignatura optativa a nivel universitario. En cuanto a las escuelas primarias y secundarias, las clases de teatro en la lengua extranjera meta se podrían ofrecer a los estudiantes como una asignatura optativa.

\section{CONCLUSIÓN}

Este artículo pretende promover el teatro como una herramienta poderosa en la enseñanza de lenguas extranjeras. Se centra en la relación entre las clases de teatro, el factor afectivo y la destreza oral. El objetivo final del artículo fue explorar los beneficios potenciales del teatro en cuanto al desarrollo de la destreza oral de las estudiantes de español en la Facultad de Filosofía y Letras en Ljubljana.

Es importante tener en cuenta que esta investigación se basa en el enfoque cualitativo, por lo cual, su propósito no es generalizar los resultados. La información se obtuvo a través de entrevistas que pretendieron recoger las experiencias personales de las estudiantes con el teatro. También es difícil aislar el impacto del teatro de otras influencias como las otras asignaturas de español que las estudiantes atendieron.

En cuanto al factor afectivo en relación con la destreza oral, los resultados sugieren que las clases de teatro son más útiles en las fases principales de aprendizaje de una lengua extranjera. En lo que se refiere a la adquisición de la lengua, los resultados sugieren que las clases de teatro tienen un impacto positivo en cualquier nivel de competencia lingüística. Por lo que respecta al factor afectivo, la investigación implica que el silencio de los estudiantes en la clase podría tener raíces no solo en la ansiedad por la lengua, sino que también por la ansiedad social. En cuanto a la adquisición de la lengua, el beneficio que fue mencionado varias veces por las estudiantes fue que el teatro les ayudó a enriquecer su vocabulario. El aumento en la participación de las estudiantes en otras clases podría ser el resultado de varios agentes. Según los datos recogidos, las clases de teatro son uno de esos factores.

Sería interesante seguir explorando el tema desde un enfoque cualitativo, usando el formato de grupo de discusión (focus group), para conseguir información de otra índole, pues entendemos que al ser el teatro una actividad grupal, la recogida de datos también debería establecerse también desde la misma dinámica. Otro ángulo interesante de una investigación ulterior sería incluir los alumnos de la escuela primaria y secundaria y comparar las respuestas de los diferentes grupos de edad entre sí. 


\section{REFERENCIAS BIBLIOGRÁFICAS}

ARNOLD, Jane Morgan (2000) La dimensión afectiva en el aprendizaje de idiomas. Madrid: Cambridge University Press.

ARNOLD, Jane Morgan (2006) Comment les facteurs affectifs influencent-ils l'apprentissage d'une langue étrangère? Ela: études de linguistique appliquée 144, 407-426. BOUDREAULT, Chris (2010) The Benefits of Using Drama in the ESL/EFL Classroom. [en línea] Iteslj.org.10 de agosto de 2019. http://iteslj.org/Articles/Boudreault-Drama.html

BOQUETE MARTÍN, Gabino (2014) Interacción y motivación en el aula: enseñar desde el teatro. E. Tobar Delgado/V. Hidalgo Martín (eds.), Arriba el telón: enseñar Teatro y desde el teatro. Madrid: Ministerio de Educación, Cultura y Deporte, 5-14. COHEN, Andrew D. (2008) Speaking Strategies for Independent Learning: A Focus on Pragmatic Performance. S. Hurd/T. Lewis (eds.), Language Learning Strategies in Independent Settings. Clevendon: Multilingual Matters, 119-140.

COMBA OTERO, Mercedes (2014) ¡No pienses, actúa!. E. Tobar Delgado / V. Hidalgo Martín (eds.), Arriba el telón: enseñar Teatro y desde el teatro. Madrid: Ministerio de Educación, Cultura y Deporte, 21.

CONSEJO DE EUROPA (2002) Marco común europeo de referencia para las lenguas: aprendizaje, enseñanza, evaluación. 19 de agosto de 2019. https://cvc.cervantes.es/ ensenanza/biblioteca_ele/marco/

ČAMERNIK, Patricija (2018) Vzgojni in izobraževalni vidiki gledališke umetnosti pri poučevanju tujih jezikov. Tesis de maestría. Ljubljana: Facultad de Filosofía y Letras, Universidad de Ljubljana.

DÖRNYEI, Zoltán (2007) Research Methods in Applied Linguistics. Oxford: Oxford University Press.

GOITIA PASTOR, Leyre (2007) Juego, representación y aprendizaje: Un taller de teatro para alumnos de E/LE. Foro de profesores de ELE 3, 103-110.

GÓMEZ GÓMEZ, Fedra (2014) Ventajas e inconvenientes del uso de las técnicas dramáticas en las clases de ELE. E. Tobar Delgado/V. Hidalgo Martín (eds.), Arriba el telón: enseñar Teatro y desde el teatro. Madrid: Ministerio de Educación, Cultura y Deporte, 68-69.

HIDALGO MARTÍN, Vanessa (2012) El teatro en la clase de ELE: Dos propuestas de taller. MarcoELE 15, 1-109.

HIDALGO MARTÍN, Vanessa (2014) Doña Gramática: un personaje con mucho carácter. E. Tobar Delgado/V. Hidalgo Martín (eds.), Arriba el telón: enseñar Teatro y desde el teatro. Madrid: Ministerio de Educación, Cultura y Deporte, 44.

HELDENBRAND, Brian (2003) Drama Techniques in English Language Learning. The Korea TESOL Journal 6(1), 27-38. 
LEMUT NOVAK, Tjaša (2009) O smiselnosti dramskih skupin v tujem jeziku. Didakta 18/19 (127), 36-41.

MALEY, Alan/Alan, DUFF (1982) Drama techniques in English Language learning (2a ed.). Cambridge: Cambridge University Press.

MICCOLI, Laura (2003) English through drama for oral skills development. ELT Journal 57 (2), 122-129.

MCCROSKEY, James/Virginia P. RICHMOND (1990) Wilingness to Communicate: A cognitive view. Journal of Social Behavior and Personality 5(2), 19-37.

MUÑOZ-BASOLS, Javier/Elisa GIRONZETTI (2018) Expresión oral. J. Muñoz-Basols/ E. Gironzetti/M. Lacorte (eds.), The Routledge Handbook of Spanish Language Teaching: Metodologías, contextos y recursos para la enseñanza del español L2. Londres y Nueva York: Routledge, 198-212.

NICOLÁS ROMÁN, Susana (2011) El teatro como recurso didáctico en la metodología CLIL: un enfoque competencial. Encuentro 20, 102-108.

PAVLIN, Luka (2017) Strah je znotraj votel, okrog pa ga nič ni - kaj pa pri tujih jezikih? Strah pred tujim jezikom pri pouku francoščine kot tujega jezika v Sloveniji. Vestnik za tuje jezike 9(1), 219-234.

RAMÍREZ MARTÍNEZ, Jesús (2002) La expresión oral. Contextos educativos: Revista de educación 5, 57-72.

ROSÉN, Linda (2018) La voluntad de comunicarse en la lengua meta en el aula de español como lengua extranjera: Un estudio cuantitativo basado en una encuesta con alumnos de un instituto sueco. [pdf] Estocolmo: Universidad de Estocolmo. 20 de agosto de 2019. http://www.diva-portal.org/smash/get/diva2:1217695/FULLTEXT01.pdf\%20\%5b6

RTVSLO.si (2009) O najstniških tegobah na odru v španščini. [en línea] 20 de agosto de 2019. https://www.rtvslo.si/kultura/oder/o-najstniskih-tegobah-na-odru-v-spanscini/158351

SÁNCHEZ CARRÓN, Irene (2013) 'Se me dan mal los idiomas': Aspectos psicológicos que pueden influir en la adquisición de lenguas extranjeras. Didáctica. Lengua y Literatura 25, $283-285$.

SIRISRIMANGKORN, Lawarn (2018) The Use of Project-Based Learning Focusing on Drama to Promote Speaking Skills of EFL Learners. Advances in Language and Literary Studies 9(6), 14-20.

SKELA, Janez (1999) Ustno sporočanje. L. ČOK (ed.), Učenje in poučevanje tujega jezika. Smernice za učitelje v drugem triletju osnovne šole. Ljubljana: Pedagoška fakulteta; Koper: Znanstveno-Raziskovalno središče Republike Slovenije, 99-114.

ŠIFRAR KALAN, Marjana (2008) Ustno sporočanje -najbolj priljubljena jezikovna zmožnost?. J. Skela (ed.), Učenje in poučevanje tujih jezikov na Slovenskem: Pregled sodobne teorije in prakse. Ljubljana: Tangram, 290-304. 
VAQUEIRO ROMERO, María Montserrat (2014) El teatro como recurso didáctico. E. Tobar Delgado/V. Hidalgo Martín (eds.), Arriba el telón: enseñar Teatro y desde el teatro. Madrid: Ministerio de Educación, Cultura y Deporte, 34-41.

WILLIAMS-FLECK, Alexandra (2014) Creating Theatre-based Curriculum for use in the ESL / EFL Language Classroom: A Model. Tesis de maestría.[en línea] San Francisco: La Universidad de San Francisco. 10 de agosto de 2019. https://pdfs. semanticscholar.org/78d9/d3c8174c86343cb036dbb86c6032602aa7b1.pdf

\section{POVZETEK}

\section{VPLIV GLEDALIŠČA NA RAZVIJANJE GOVORNIH SPRETNOSTI IN NIŽANJE RAV- NI ČUSTVENEGA FILTRA PRI POUKU ŠPANŠČINE KOT TUJEGA JEZIKA}

Ta članek se osredotoča na odnos med poukom gledališča, čustvenimi dejavniki in govornimi spretnostmi. Glavni cilj članka je raziskati morebitne pozitivne učinke gledališča na razvoj govornih spretnosti študentov. Empirični del je sestavljen iz analize polstrukturiranih intervjujev s skupino študentk španščine, ki so prisostvovale pri predmetu Špansko gledališče. Skozi analizo osebnih izkušenj intervjuvank z gledališčem ta raziskava proučuje naslednje vidike uporabe gledališča pri pouku tujih jezikov: odnos med sodelovanjem pri urah gledališča in ravnjo čustvenega filtra, povezavo med sodelovanjem pri urah gledališča in usvajanjem jezika, ter vpliv sodelovanja študentk pri gledaliških urah na njihovo dejavno sodelovanje pri drugih urah. Glede govornih spretnosti in ravni čustvenega filtra so rezultati pokazali, da je imel pouk gledališča pozitiven vpliv. Študentkam je namreč sodelovanje $\mathrm{v}$ gledaliških dejavnostih pomagalo izgubiti strah pred delanjem napak med govorjenjem v španščini. Kar se tiče ustnega sporočanja in čustvenih dejavnikov, rezultati nakazujejo tudi, da so pozitivni učinki sodelovanja pri pouku gledališča najbolj opazni v začetnih fazah usvajanja tujega jezika. Poleg tega pa rezultati nakazujejo, da molčečnost študentov v razredu ni vedno povezana le s strahom pred tujim jezikom, pač pa je lahko povezana tudi s socialno anksioznostjo. Pouk gledališča je prav tako študentkam pomagal izboljšati njihovo poznavanje tujega jezika. Izkazalo se je, da je imelo gledališče na vseh ravneh jezikovnega znanja ki jih je zajela raziskava pozitivne učinke na usvajanje tujega jezika. Dejstvo, da študenti bolj dejavno sodelujejo tudi pri drugih urah je lahko rezultat večih dejavnikov (na primer: obšolskih dejavnosti). Rezultati kažejo, da je pouk gledališča eden od teh dejavnikov.

Ključne besede: pouk tujih jezikov, španščina kot tuji jezik, zmožnost ustnega sporočanja, čustveni dejavniki, pouk gledališča 


\section{ABSTRACT}

\section{THE INFLUENCE OF THEATRE ON DEVELOPING SPEAKING SKILLS AND LOW- ERING OF THE AFFECTIVE FILTER LEVEL IN THE SFL CLASS}

This article focuses on the relationship between theatre classes, affective factors, and speaking skills. The article's main goal is to explore theatre's potential positive effects on the development of students' speaking skills through an analysis of semi-structured interviews with a group of university students of Spanish who took part in a Spanish theatre class. Through the analysis of the interviewees' personal experience with theatre, this research examines the relationship between participation in a theatre class and the affective filter level, the link between participation in a theatre class and language acquisition, and the relevance of student participation in a theatre class with regard to their engagement in other classes. Regarding the speaking skills and the affective filter level, the results show that participation in the theatre class had a positive impact. Students' participation in the theatre class helped them get over the fear of making mistakes when speaking Spanish. According to the results, theatre classes have the most notable positive impact on the progress of beginners. The results also indicate that when students are silent in class, this may not only be related to language anxiety, but also to social anxiety. The theatre class aided students in improving their knowledge of a language. The findings suggest that theatre classes have a positive influence on language acquisition at all language competence levels that were included in this research. The increase in students' participation in other classes may be brought about by various agents. The results suggest that theatre classes are one of these agents.

Keywords: foreign language classes, Spanish as a foreign language, speaking skills, affective factor, theatre classes

\section{RESUMEN}

Este artículo se centra en la relación entre las clases de teatro, el factor afectivo y la destreza oral. Su objetivo principal es explorar los potenciales beneficios del teatro en el desarrollo de la destreza oral a través de un análisis de entrevistas semi-estructuradas con las estudiantes universitarias de español que participaron en la clase Teatro español. Mediante el análisis de sus experiencias personales, se examinan las siguientes facetas: la relación entre la participación en una clase de teatro y el nivel del filtro afectivo, la conexión entre la participación en una clase de teatro y la adquisición de la lengua y la relevancia de la participación de las estudiantes en la clase de teatro por su involucramiento activo en otras clases. En cuanto a la destreza oral y el nivel del filtro afectivo, según los resultados, la participación en la clase de teatro tuvo un impacto beneficioso; les ayudó a perder el miedo de hablar en español. Los resultados sugieren que el efecto positivo de las clases de teatro es más notable en el progreso de los principiantes. Si los estudiantes guardan silencio en la 
clase, esto puede relacionarse tanto con la ansiedad conectada con la competencia lingüística como con la ansiedad social. La clase de teatro ayudó a las estudiantes de todos niveles de competencia lingüística a mejorar su conocimiento de la lengua extranjera. El aumento de la participación activa de los estudiantes puede ser el resultado de varios factores, entre los cuales también se encuentran las clases de teatro.

Palabras clave: clases de lenguas extranjeras, español como lengua extranjera, expresión oral, factor afectivo, clases de teatro

\section{ANEXO: CUESTIONARIO EN ESPAÑOL PARA LAS ENTREVISTAS}

1. ¿Cómo evalúas tu habilidad de comunicación oral en español? ¿Cuándo hablas, puedes expresar en español todo lo que quieres decir de modo normal?

2. ¿Cómo te sientes cuando tienes que hablar en la clase de español de modo normal? ¿Sientes miedo/incomodidad/ansiedad? ¿Por qué?

3. ¿Cuál es tu estrategia respecto a, por ejemplo, debates en clase? ¿Hablas voluntariamente? ¿Participas si te llama el profesor? ¿Prefieres no intervenir?

4.1. ¿Fue esta la primera clase de teatro en la que participaste?

4.2. ¿Por qué escogiste esta asignatura? ¿Qué esperabas de la asignatura? ¿Cumplió con tus expectativas?

5. ¿Cómo te sentiste cuando tuviste que actuar en español delante de la profesora y tus compañeros de clase?

6. ¿En qué áreas crees que esta asignatura te ayudó más? ¿Y en el sentido emocional? ¿Cómo te ayudó en cuanto a la lengua?

7. ¿Cómo influyó la participación en la clase de teatro en tu destreza oral en español?

8. ¿Te acuerdas de alguna actividad hecha en la clase de teatro que te ayudó a ti y a tus compañeros a perder el miedo de hablar en español?

9. ¿Piensas que ahora hablas con más naturalidad/fluidez/corrección? ¿Te sientes más relajada cuando tienes que hablar en las clases de español?

10. ¿Crees que ahora también participas más (hablas más, preguntas más) en otras clases?

11. ¿Qué tal los otros compañeros? ¿Crees que los que lucharon con la ansiedad cuando tuvieron que hablar también progresaron?

12. ¿Te gustaría participar en otra asignatura de este tipo? ¿Por qué sí/no? 